Article

\title{
Cultural Sustainability: Teaching and Design Strategies for Incorporating Service Design in Religious Heritage Branding
}

\author{
Tsen-Yao Chang * and Yu-Ju Chuang
}

check for updates

Citation: Chang, T.-Y.; Chuang, Y.-J. Cultural Sustainability: Teaching and Design Strategies for Incorporating Service Design in Religious Heritage Branding. Sustainability 2021, 13 , 3256. https://doi.org/10.3390/ su13063256

Academic Editor: Marek Nowacki

Received: 25 February 2021

Accepted: 11 March 2021

Published: 16 March 2021

Publisher's Note: MDPI stays neutral with regard to jurisdictional claims in published maps and institutional affiliations.

Copyright: (c) 2021 by the authors. Licensee MDPI, Basel, Switzerland. This article is an open access article distributed under the terms and conditions of the Creative Commons Attribution (CC BY) license (https:/ / creativecommons.org/licenses/by/ $4.0 /)$.

\author{
Department of Creative Design, National Yunlin University of Science and Technology, Yunlin 640, Taiwan; \\ juyuchuang@gmail.com \\ * Correspondence: changty@gemail.yuntech.edu.tw or changty8908@gmail.com; Tel.: +886-5-5362601 (ext. 6416)
}

\begin{abstract}
Under globalization, a local brand must be managed by strengthening local uniqueness and representativeness to become a unique brand that is irreplaceable in the international market. An examination of Taiwan's cultural characteristics and resources shows that religion has been the focus of the government's tourism promotion in recent years. A religious site is filled with architectural, historical, aesthetic, and cultural elements. Through online marketing and multilingual introductions, the government has packaged Taiwan's religious culture into a brand. Temples not only provide devotees with a place for spiritual sustenance but also offer them cultural tourism experiences. When service design is integrated into the branding process, the various touchpoints experienced are the key to promoting temple and tourist interactions. A culture can be converted into unique and representative patterns by using brand design strategies, thereby creating opportunities for cultural sustainability. This study chose a national monument temple in Yunlin County, Taiwan, as the study location. Through a course of instruction, students with professional design backgrounds were granted the opportunity to work in a monumental temple, where they practiced participatory learning, played the role of mentors, and developed design proposals. By using observation and interview methods as well as service design tools, the students identified problems and needs and proposed service design insights and design implementation plans. The results of this study were analyzed along with the design flow, course outcomes, and students' open-ended questionnaires. Finally, a religious branding design strategy based on the core value of cultural sustainability was proposed.
\end{abstract}

Keywords: service design; experience design; religious culture

\section{Introduction}

The diverse and open religious cultures in Taiwan, coupled with signature tourism and local cultures, are characterized by different development directions. Given the diverse development and integration of Taiwanese religious cultures in everyday activities, experiencing religious cultures has become one of the vital ways for tourists to experience local culture. According to the 2019 statistical data published by the Ministry of the Interior [1], Taiwan boasts a total of 12,279 temples. If these religious buildings are further examined in terms of historical scale, there are actually 217 government-certified monuments and historic buildings in Taiwan associated with Buddhism and Taoism or Folklore Religion, as shown in the overview of government-certified religious cultural heritage on the Taiwan Religious Culture Map (www.taiwangods.com) (accessed on 30 January 2020), which is a website established by the Ministry of the Interior. The Ministry of the Interior's purpose in setting up this website is to highlight the development potential of religious cultures. Through systematic integration, the website aims to help local citizens and foreigners to understand Taiwan's religious cultural heritage and provide them with practical guides and information on religious tourism activities in the country.

Religious tourism generates a positive influence on regional cultural development by strengthening traditional cultures and extending travel seasons [2]. Taiwan features 
religious inclusion and diversity. Local management, along with changes in travel patterns, features specific religious cultural heritage, such as beliefs, history, culture, and art, which are important to developing in-depth tourism. The cultural value of religious heritage encompasses tangible assets, such as buildings, Buddha statues, and objects, as well as intangible assets, which include sacrificial rituals/ceremonies, traditions/customs, and local solidarity. Among these, assets that have become cultural heritage exhibit traditional, artistic, and historical significance that must be preserved and passed down through generations. In addition, exploring the development of religious tourism in Taiwan from an industry perspective involves researching issues related to the management of religious cultural fields, transmission of ideology, and the process of seeking blessings from the perspective of service design. Through different touchpoints, customers are able to perceive value, connect with others, and create travel experiences during the process of experience [3]. Touchpoints include physical facilities, indicators, promotional materials, and products sold at the site. These "experiences" are created at all times through different service touchpoints [4] and distributed across each part of the experience process. Touchpoints are generally an essential basis for customers to interact and experience services [5]. In religious branding, interactive touchpoints with devotees and tourists are created by developing, marketing, and gifting products in order to enhance religious travel experiences and increase opportunities for religious cultural transmission.

In Taiwan, temples are largely operated by management committees or foundations given their historical context and laws and regulations. For this reason, temples are managed differently, and no compulsory regulations and templates are available. Temple operators believe that determining methods to promote their religious beliefs and attracting devotees and tourists, as well as achieving sustainable operation, are not the only focus of temple management or the mission of cultural heritage organizations, but they are also the key to brand development. This study incorporated brand strategies and service design concepts in the management of temples. Using Mailiao Gongfan Temple in Yunlin County, Taiwan as the subject, this study employed course designs in order to examine, merge, and develop teaching and design strategies for religious branding through the process of research, investigation, and implementation. Multiple roles, such as teachers, students, temple operators, and local residents, participated in the process, thereby establishing the distinctiveness and uniqueness of religious brands, as well as emphasizing and highlighting the cultural value of temples in order to create a foundation for the sustainable operation of religious brands.

\section{Literature Review}

Culture is the key factor in creating local distinctiveness. Keesing [6] defined culture as a specific social group's behavioral traits and mode of social transmission. Warnier [7] asserted that culture is a complex body and that all cultures are uniquely, geographically, and socially localized. Culture features depth and breadth. It can be interpreted and understood from different dimensions. Different understandings of culture can be obtained at various levels of cultural performance. When a brand, product, or experience is infused with cultural elements, it resonates with consumers because culture highlights sensible and emotional characteristics. The value, ideals, and vocabularies of different countries can be communicated through cultural products. Overdependence on imports may slowly eradicate the existence of culture that is native to a local area [8]. Stanley Yen [9], a hotel entrepreneur in Taiwan, believed that leading the country to the world stage and assimilating with traditional and international/modern self-culture are important to marketing. In doing so, culture not only provides brands or products with a unique identity that distinguishes them from competitors, but it also enhances consumer identification with the brand or product. Understanding and utilizing culture as well as the potential of developing culture as a source of nourishment for design development is taken into account from the perspective of service design. 


\subsection{Cultural Sustainability: The Tourism Benefits of Religious Culture}

Taiwan has over 12,000 registered temples according to 2019 statistics [1]. A number of religious sites have been developed into internationally renowned tourist attractions. Events that celebrate religious beliefs deeply characterize the religion they are associated with, and these attract large groups of tourists and create many business opportunities and advantages. In addition, the 2016 Summary Report of Cultural Tourism Output Estimates published by the Ministry of Culture [10] indicated that $29.9 \%$ of Taiwanese citizens participated in recreational activities that offered cultural experiences; specifically, $9.4 \%$ of them attended religious events and $7.6 \%$ joined events that cultivated appreciation of cultural heritage. This trend showed the development potential of religious tourism. Tourism destinations are attractive. Goeldner and Ritchie [11] indicated that the scope of tourist attractions is considerably broad and generally refers to the sum of all attractions that interest visitors. They categorized attraction attributes into five main groups: cultural, natural, events, recreation, and entertainment. Cultural attractions include monuments, archeological sites, and buildings. Event attractions include festivals and religious events. These attractions reflect the development potential of religious tourism and have become distinct elements that attract tourists due to their richness in value and meaning, both culturally and historically. For example, this research refers to the religious site Mailiao Gongfan Temple in Yunlin County, Taiwan (https:/ / kongfan.whgroup.life/) (accessed on 15 January 2021), which has held special festivals every year for a long time. Those festivals which entwine cultural and historical significance in traditional activities always attract believers and tourists from everywhere to attend. Such a phenomenon reflects the potential of religious tourism and the influence of religion on the local economy.

Religious tourism is part of cultural tourism. Religion and culture are closely related. The depth of cultural content cannot be overlooked in religious tourism. Religious tourism is a type of tourism activity in which participants are totally or partially motivated to join for religious purposes. Religious tourism is the oldest form of tourism [12,13]. Types of tourism have evolved with changes in lifestyle and consumer preference. The Organization for Economic Cooperation and Development (OECD) published a report in 2009 [14] that analyzed the relationship between tourism and culture, as well as the attractiveness and competitiveness of tourist destinations. Various forms of tourism, ranging from heritage tourism and cultural tourism to creative tourism, reflect the different spending behaviors of consumers and the development of the experience economy. Previously, consumption patterns in cultural heritage tourism involved products and focused on selling products derived from a heritage site. Countries and regions that do not have heritage sites for tourism development normally use culture as an approach to enable tourists to experience past and present local cultural atmospheres. Therefore, religious tourism, with abundant cultural resources, has gradually become a popular attraction in economic development [15]. Many countries recently have invested actively in cultural tourism resources [16], and religious culture is also an important tourism resource.

The relevant research issues of religious culture and cultural tourism include cultural assets, cultural marketing, cultural touchpoints, cultural derivative products, festival design, and cultural heritage, which have gradually expanded the scope of religious and cultural research. The religious experience which engages with the emotional and immersive experiences is accompanied by the form of service in the ritual process under specific cultures, and there is an influential relationship between experience quality, perceived value, and satisfaction of the tourist service experience [17]. According to Yan and Hsieh (2019) [18], the travel motivations and cultural difference can influence event participation. The specific cultural rituals of religion could create a unique emotional experience for participants. Therefore, when considering the issue of religious tourism, it is not the same as ordinary tourism. The biggest difference between them lies in the special rituals derived from religious culture and religious loyalty [19], which also have influence on their marketing methods. In addition, religion, through the belief and recognition of the people, is able to create a kind of in-depth comfort and mental support. In such a situation, the 
consuming experience that takes place during religious activities is different from ordinary commercial consumption, instead instilling more spiritual dedication [20].

On the other hand, temples at religious sites are largely constructed with sophisticated architectural craftsmanship and skills and are regarded as historical and artistic assets in Taiwan. Generally, temples provide a place for local people and residents to gather. Moreover, they can boost the development of neighboring industries. According to Hong and Hsieh [21], religious culture does not only influence hardware facilities but also imposes certain requirements on software, i.e., management and service, including the need for knowledge of religious culture. Service experiences revolving around the topic of religion must simultaneously consider the correct understanding and application of religious culture.

\subsection{Brand-Added Value: The Integrated Design and Thinking of Religious Culture}

Culture and economy have a reciprocal and mutually beneficial relationship [22]. Economy encompasses all forms of commercial activities. Given its relationship with the economy, culture can be manufactured, produced, and manifested into various physical commodities or travel experiences. Because of stories and emotional elements in cultural content, economic activities lead to emotional resonance, which in turn increases the heterogeneity and distinctiveness of these activities. From the perspective of consumers, a brand not only facilitates product sales but also communicates the value of a service and experience, with "experience" as the key in business transactions [23]. When religious culture is integrated into an experiential activity to understand local culture, the activity becomes a method for experiencing religious culture, which is not only a cultural and creative economic activity but also a process through which religion develops into a brand.

In a modern, service-oriented social structure, the key to dominating the consumer market does not merely focus on product quality, techniques, or sales capability. Service providers must develop a strong sense of service and possess service perception and experience to further understand the real needs of consumers and to strive to meet these needs [24]. The aesthetic experience of products is considered vital in consumer behavior [25]. Danish futurist Dr. Rolf Jensen proposed that by shopping, consumers seek underlying stories as well as the affective experiences and connections that are embedded in products [26]. For consumers, product selection includes not only consideration of the functionality of products but also the intangible mental satisfaction that the products bring [27]. Consumers are no longer interested in mass-produced, institutionalized products [28] (p. 46). Therefore, designers tend to transform commodities into mediums for cultural transmission through product designs, so that commodities are made to fulfill their functionality and also satisfy consumers' emotional, aesthetic, and social demands [29]. Based on the aforementioned arguments, because of changes in the consumer market and consumer preference, design thinking should be more diversified. Brown [30] proposed three core steps in design thinking: inspiration for searching solutions, ideation for developing and testing ideas that may lead to solutions, and implementation for charting a path to the market. Through this process, a design is completed step by step.

When business operation shifts from a seller's market to a buyer's market, design thinking facilitates research, development, and manufacturing to better meet user needs and gain market opportunities that help to build and obtain brand value and necessity so as to achieve sustainability of business operations. Brand image has long been regarded as a crucial concept in marketing [31] and an essential foundation for gaining competitive edge and for distinguishing and managing brands. It is also a method for creating product differentiation [32,33]. Not only can brand image drive brand equity and create brand value, but it can also be a source of brand loyalty [34]. The spirit of an established brand is communicated to consumers through brand elements, such as brand name, logo, symbols, and symbolic objects [35], which subsequently create differentiation and distinctiveness. In terms of the tourism market, Korean scholars Kim and Lee [36] used traveling in South Korea as an example to point out the lack of originality and difference among tourism 
commodities that had led to more intense competition, with branding as an effective method to win consumers' belief and be able to connect their emotional experiences [37]. On the other hand, the particularity of religious traveling can serve as an image boost for local development [38]. Introducing the brand strategy with religious culture, it is able to incorporate image particularity for tourism development, highlight intrinsic religious value, and further promote religious culture. Designing a brand strategy of a religious site, it is possible to build a concrete image for religious and cultural marketing, attracting tourists' eye-tracking, and finally bringing potential tourism opportunities for revitalizing the local economy.

\subsection{Service Experience: Service Design Perspective Based on Religious Culture}

Service design is based on the needs and perceptions of people and simultaneously employs system thinking and design thinking to form a complete design method [39]. It is not a novel design approach but a holistic, integrative, multidisciplinary field. The process of service design achieves service innovation by introducing professional design procedures into service designs, thus proposing a service journey that satisfies the demands of service receivers and service providers [40]. When service design is used in the tourism industry, service design tools such as persona, customer journey map, blueprint, and stakeholder map can be employed to examine consumer groups at tourism destinations and problems (gaps) that arise during their journey. The obtained results are then used to correct and enhance overall service quality. These activities and tools can be used to facilitate multidisciplinary cooperation, communication, and ideation by designers [41] Using the observations and user-centered thinking that are emphasized by service design in different discussions and fields reveals the touchpoints and stakeholders at various stages, which are then used to produce different perspectives and directions of thinking.

Regarding the tourism experience, Dean MacCannell pointed out that tourist attraction stems from the empirical relationship between tourist, sight, and marker. The term marker refers to intermediaries, including promotional materials, brochures, travel books, and materials that communicate travel information [42]. An intermediary is conceptually similar to service touchpoints in service design, except that service touchpoint is a broad term. Service touchpoints link service providers to customers, which is crucial for the customer experience [43]. Touchpoints commonly found in religious settings (the main places of worship in Taiwan, such as Buddhist monasteries or Taoist temples) include promotional materials, good-luck charms, and relevant merchandise. Chang [44] indicated that religious souvenirs represent not only transactions for the sale of merchandise between buyers and temples but also a gift exchange between people and the deities that they worship. Therefore, the purpose of selling religious merchandise is to cover the cost of temple operations and more importantly to express religious beliefs, develop a positive attitude towards life, transmit the religious culture and spirit into physical goods, and achieve the physical touchpoints of religious culture marketing. Therefore, when introducing service design thinking into the religious tourism experience, the designers are able to create the relevant touchpoints, such as religious propaganda and products, which become communicative assistance for religious marketing. The touchpoints of service design involve not only the use of cultural promotion, but more importantly building the religious connotative system for the transmission of cultural narratives and the traditional history of religion itself instead of fragmented legend, and can even be extended to link the local cultural experience and characteristics.

Using this perspective to study the service touchpoint design in religious settings reveals that various service design tools facilitate collection, analysis, and comprehension of the benefits of religious culture, as well as the formulation of development strategies. When service design is implemented, it is important to consider and plan the integrity of its content in detail, which includes communication, environment, and behavior; regardless of the form it adopts, the content must be consistent, user friendly, and strategically combined [45], in order to provide an appropriate service solution that can integrate 
local culture, tourism, service, and experience and create innovative content for religious tourism. Integrating religious culture with educational experience into contextual histories can create memorable narratives in order to promote the perceptions of tourists; as Kelly and Littman (2008) described, "The power of a good story has a few thousand years behind it." [46]. Metaphysical experience can promote tourist perception by introducing religious cultural and educational content and providing cultural introduction through strategic brand image development to improve tourists' cultural understanding [47]. Using service design in branding strategies for religious cultural fields, exploring the design's innovative thinking and model, and applying it to culturally connected religious products can not only allow tourists to take away blessings, but also help the context of religion to convey belief through design effect, enhance tourists' understanding of religious culture, and strengthen the impression left by religious branding. In this study, the core concept of applying service design for planning creative teaching and design strategies in a religious tourism project is expected to educate the public by providing comprehensive service experience and positively marketing intrinsic religious culture through understanding and studying types of religion rather than offering a commercial, consuming experience.

\subsection{Teaching Practice in Religious Heritage Branding}

In 2013, the Ministry of the Interior announced the Religious Cultural Creative Fertile Ground Plan in Taiwan, encouraging citizens to recognize the country's cultural landscape and the traditions established throughout the history of religion. By promoting tourism activities, the Ministry of the Interior hopes to maximize the effects of the cultural and creative industries. Religious beliefs in Taiwan are diversified. Religious history and culture, rituals and ceremonies, craftsmanship, and architecture are tangible and intangible cultural assets of Taiwan. If these religious experiences can be systematically and intellectually planned, considerable economic benefits can be generated and the foundation for sustaining the operation of religious cultures can be reinforced in an environment where religious culture is valued.

In Taiwan, policies have been implemented to promote the development of religious tourism, which is classified into four types of experiences, according to Pine and Gilmore [48]: entertainment, educational, escapist, and aesthetic. In terms of educational experience, the historical context of religion and the educational value of classic stories can create spiritual and educational experiences. The tranquil atmosphere at religious sites provides an escapist experience. The craftsmanship and architectural skills involved in building religious sites offer an enriching aesthetic experience. Entertainment experiences are created along with traditional cultures or festivals during various types of celebratory activities, providing tourists with different experiences and forms of enjoyment. In other words, religious tourism is capable of developing and creating different types of experiences. The literature review in this study highlights the importance of service touchpoints in customer experience. Furthermore, branding is the key to achieving content differences that can attract customers. Therefore, in developing religious tourism, an inventory of concrete artifacts in religious culture (e.g., monumental buildings and works of artistic craftsmanship) and non-concrete cultural value (e.g., prayer and sacrificial ceremonies or cultural customs) can be developed using branding skills to infuse unique identity into religious sites. Thus, brands that are well-positioned provide consumers with an attractive set of strong associations [49]. Subsequently, designs related to tangible and intangible touchpoints (through religious cultural marketing and cultural products, etc.) can be developed and branded to provide design thinking for the branding of religious sites. To promote religious culture with a brand-building strategy is a value-added marketing process in order to accumulate the loyalty of a religious brand through the design process and to endow religious marketing with branding thinking.

Based on a comprehensive consideration of locality studies, the representativeness of religious culture, and the possibility of future cooperation, the national monument Mailiao Gongfan Temple, in Yunlin County, Taiwan, was selected as the subject for design 
implementation in this study. By incorporating service design thinking and tools, this study adopted integrative thinking and system thinking to examine and analyze various design problems through staged course designs and design operations. Based on the discussions, reflections, and revisions made by the teachers, students (designers), and temple operators involved in the teaching process, the researchers of this study proposed service touchpoint designs for religious sites and constructed design strategies and models that employ brand-based design thinking to establish opportunities for sustaining the development of religious brands.

\section{Methods}

This study involved experimental teaching and design implementation spanning over a period of one year, during which the Gongfan Temple, which is a religious cultural site representing Yunlin, was chosen as the subject and area for design implementation. In the first semester, the course was taught to third-year undergraduate students with emphasis on the application and implementation of service design tools. In the second semester, the course was taught to first-year undergraduate students; six third-year undergraduate students who took the course in the first semester were selected to mentor first-year students. The course for first-year students emphasized creative thinking, which enabled students with design experience to participate and develop different design ideas. After the full-year course ended, students who took the course were invited to join a design project, which involved submitting proposals, participating in discussions, making modifications, and completing the project according to the design service requirements of Gongfan Temple through actual operation of an industry project. The results of the project included a guidebook for Gongfan Temple and a rice packaging design. The design implementation course with emphasis on service design application was combined with the industry's practical requirements to propose a design implementation strategy.

\subsection{Research Framework}

The entire research process was based on an action research approach that involves the cycle of planning, action, observation, and reflection. In planning, a literature analysis of related studies was first conducted to provide a theoretical foundation for planning the teaching process design. Through teaching implementation and teaching content analysis, students' learning status and the appropriateness of teaching materials were examined. Finally, the strengths and weaknesses of the entire process were taken into account for revising and improving future course designs. In the first stage, the course was designed to allow students to conduct field investigation, followed by a non-participant observation using service design tools for analysis. Various problems were defined and firsthand data obtained from the process were combined with literary data for comprehensive analysis. The results were used to implement a design, thus completing the course in the first semester. In the second stage, purposive sampling was adopted with the selection of six students who completed the course in the first semester, to act as course mentors for the following semester. These mentors guided first-year students in the design process. In the third stage, through design practices and operations, three students actually designed proposal plans with the temple committee; they also participated in the religious branding process and presented results for verification (see Table 1). 
Table 1. The three-stage course.

\begin{tabular}{cccc}
\hline Content & Stage 1 & Stage 2 & Stage 3 \\
\hline Teaching Focus & $\begin{array}{c}\text { Field investigation } \\
\text { Service design tool } \\
\text { application } \\
\text { Design methods }\end{array}$ & $\begin{array}{c}\text { Creative thinking } \\
\text { Design methods } \\
\text { Communication }\end{array}$ & $\begin{array}{c}\text { Industry practices } \\
\text { Design proposals }\end{array}$ \\
$\begin{array}{c}\text { Design Implement- } \\
\text { ation Focus }\end{array}$ & $\begin{array}{c}\text { Religious service } \\
\text { touchpoint design }\end{array}$ & $\begin{array}{c}\text { Design thinking } \\
\text { and ideation }\end{array}$ & $\begin{array}{c}\text { Integrated design } \\
\text { Implementation of } \\
\text { industry-academic } \\
\text { collaboration projects } \\
\text { Design marketability }\end{array}$ \\
\hline
\end{tabular}

The first-stage course was taught to third-year undergraduate students. The course was taught in four stages: research, drafting, prototyping, and presentation. In the research stage, exploratory planning was first conducted; before the commencement of the course, students collected data by using service design tools and engaged in self-learning of information relevant to brand planning. The purpose of this process was to reduce students' bias in brand operation. After learning the basic concept, the students began field observations, proposed design ideas based on these observations, and made drafts of their design and plan. Next, they proposed prototypes of merchandise and brand plans, implemented them, and produced the final products. During this process, the students discussed with their mentors, carried out revisions, and reflected on the direction of their brand planning and product/field designs. In the end, they presented a complete brand plan for the religious culture of Gongfan Temple as well as a series of product designs.

The second-stage course was taught to first-year undergraduate students as a continuation of the first-stage course on the application of service design tools. Data collection, organization, and ideation were conducted by first-year students to achieve divergent thinking related to religious culture and creative designs, with a focus on training students' creativity and ideation, as well as design thinking capabilities. In addition, six fourth-year undergraduate students (students who took the course in the previous semester) were appointed as mentors to first-year students, responsible for sharing their experiences. These mentors organized textual and graphical data relevant to Gongfan Temple and used them in design proposals. Moreover, they converted cultural images and totems for design application, assessed shortcomings in the previous academic year's design outcomes, inculcated creative design thinking methods into first-year students, and created another design proposal. Stage 3 took place after the course. Three students who completed the course joined a design project, which involved working with the committee of Gongfan Temple to produce formal design proposals. In this process, the students served as designers and the teachers as facilitators, undertaking industry commercial design projects. Students were required to absorb and apply the knowledge that they had learned during the semester, including data collection and analysis, field observation, and interviews. They also translated results into design proposals. They worked with Gongfan Temple's operators to make plans and proposals and finally produce a complete set of product packaging and guidebook design.

\subsection{Research Scope and Participants}

This study selected Mailiao Gongfan Temple in Yunlin County, Taiwan, as the subject for design implementation. Gongfan Temple is the religious center of Mailiao Township and a designated national monument. In recent years, the temple's committee has supported efforts to infuse religious elements into designs and creation and has shown willingness to develop a brand for the temple and operate the temple with a forward-thinking approach. Gongfan Temple is a national monument with over 300 years of history. Its architecture showcases creative craftsmanship through stone sculptures, cochin ware, and color paint- 
ings, all of which are a rich source of artistic foundation and design ideas. Therefore, this temple was selected as the study location for teaching and applying design practices.

Gongfan Temple is also frequented by many visitors, who served as interview subjects for the students. The students were able to interact with these people, which helped to improve their ability to communicate with others and to express themselves. Since Gongfan Temple is sufficiently resourced, design courses are integrated with service design, integrated design, brand design, packaging design, and other design aspects and contents. Thus, service design is utilized to train students to identify, define, and solve problems. Subsequently, integrated design thinking is incorporated to enable students to think of design ideas, adopt ideas, use designs as solutions to problems, apply new knowledge, make design directions more specific through brand and packaging designs, attempt to translate cultural elements at the study location into various applications that have design sense, and identify directions for the innovative development of religious cultural sites. The course was offered for two semesters to third-year and first-year undergraduate students. At the end of the course, the students participated in a project and presented their final design.

\subsection{Research Methods and Instruments}

This study was based on the core value of religious tourism development. Gongfan Temple as the subject of the study was also verified. Problems in temple development were examined using service design tools on-site. Brand development goals were established by planning designs to improve the current status, and further innovations were implemented after the brand was established.

This study was conducted using a design flow composed of four stages: discover, define, develop, and deliver (collectively called 4D). Conceptually, creative thinking is carried out in a diverge-converge-diverge-converge way [50]. First, in the discovery phase, the current status of the temple was determined through field investigation, followed by a non-participant observation of tourists entering and leaving the Gongfan Temple. Subsequently, service design tools were used to conduct analysis and produce a customer journey map of the target field, from which various problems were defined. Next, the problems identified from observations and data obtained using service design tools were used to define problems, identify problems that tourists encounter on-site, and develop a solution to these problems. In addition, the qualitative data codes obtained during the service design process were combined with literary data for comprehensive analysis of the frame design process in religious branding and for design verification in the delivery phase.

\subsection{Implementation Method and Data Collection Method}

The entire study was conducted in two parts. Part 1 involved students from the first semester, who joined the project and were asked to develop design content; Part 2 required student designers to propose designs based on the needs of the client. When the students visited the study location, they first gained an understanding of Gongfan Temple before creating a design. Through this learning process, increased awareness of cultural heritage was achieved. The students attended the course to learn more about Mailiao Gongfan Temple in Yunlin County and its history, culture, and art. In terms of service experience at Gongfan Temple, the comprehensive design process required students to understand the temple's spatial arrangement as well as problems that could occur during the visit process and to propose solutions accordingly. Skills are also required in branding, packaging, and product design to enable students to develop systematic and procedural design planning methods.

In the design process (Figure 1), teachers played the role of action researcher by observing and reflecting on the students' performance in various stages of the design process. By continually discussing design concepts with the students, the teachers were able to determine their level of involvement and provided guidance for developing a broader design thinking that enabled students to think outside of the box. The selection of 
the study location allowed students to design more purposively. In narrowing the design scope, the students were found to perform differently when dealing with the same issue. At the end of the course, they were asked to complete an open-ended questionnaire and provide course feedback and opinions.

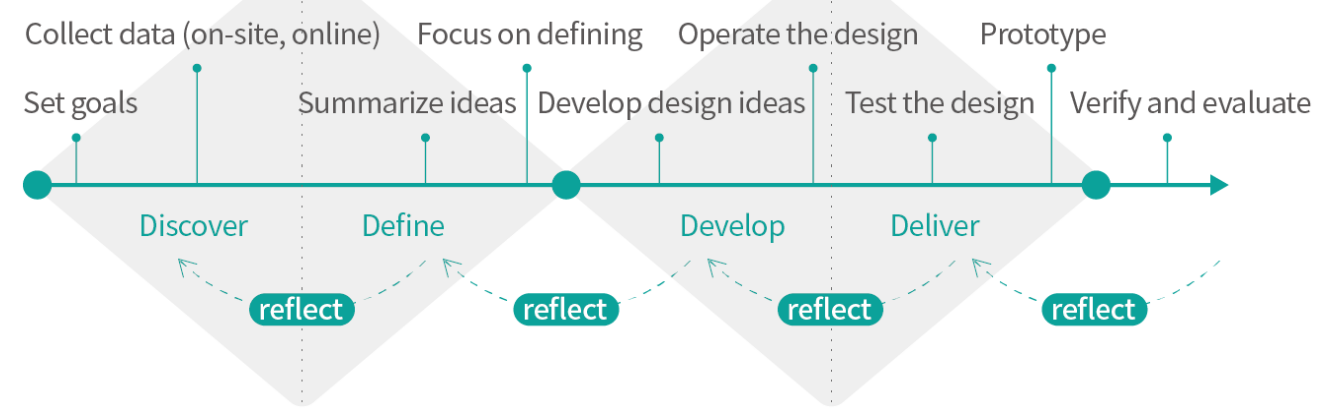

Figure 1. The $4 \mathrm{D}$ design flow.

\section{Results and Discussion}

In this study, the course was implemented in three stages, which formed a cycle. Specifically, third-year, first-year, and fourth-year students were invited to design service touchpoints for Gongfan Temple. The design process involved concept proposal, model production, and presentation of the finished product, which granted students the opportunity to experience the entire process of providing branding strategies and services to Gongfan Temple. The results were discussed in terms of learning outcomes and design implementation. The topics for discussion were: feedback on learning effectiveness, service design use, discovery of design elements, and integration of culture into courses.

\subsection{Feedback on Learning Effectiveness: Discovering Culture and Improving Professional Competency}

In the first stage, a course was offered to third-year students, which revealed their creativity in developing product proposals and models with religious cultural relevance for Gongfan Temple. Figure 2 (designed by Chang Tsen-Yao, Liao Yi-Ting, Chou Shu-Lin) presents a relatively complete religious cultural design for Gongfan Temple. The figure shows the perspectives adopted by the students to address religious cultural issues, and how they employed their creative skills to produce a design that exemplified the problems that they observed during the on-site service process.

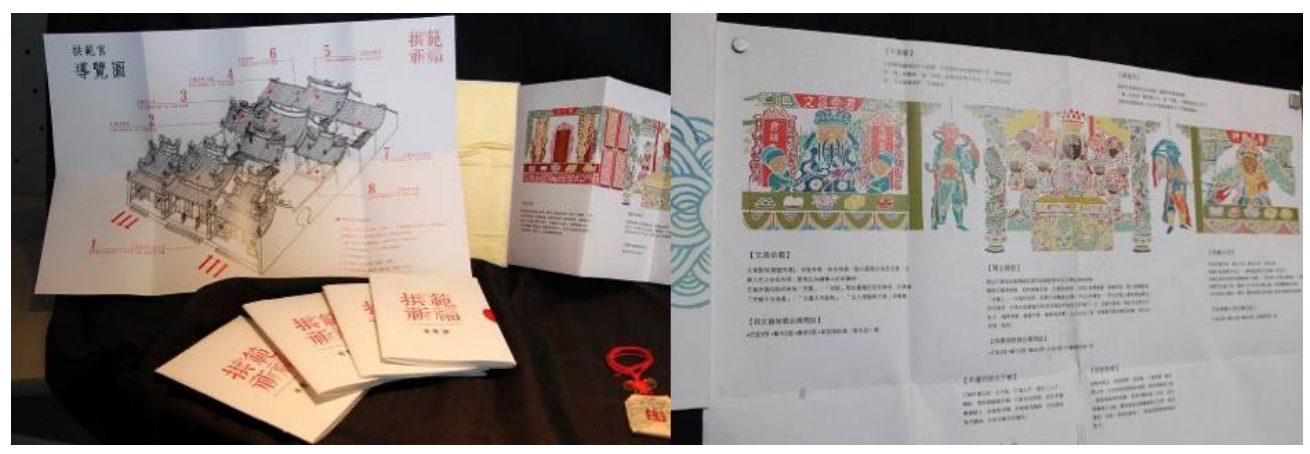

Figure 2. Gongfan Temple Guidebook.

\section{Gongfan Temple Guidebook}

The guidebook provides a graphical introduction to the spatial configuration of Gongfan Temple. Promotional material that contains detailed and clear information is made 
available to worshippers and devotees. With introductions to the various deities worshipped in Gongfan Temple, the guidebook is functional, aesthetically appealing, and fulfills the purpose of promoting cultural heritage and teaching.

\section{Sandalwood for Seeking Blessings}

Sandalwood was redesigned to match the craftmanship and creative interior design of Gongfan Temple. It is transformed into different varieties and images to emphasize its relevance to Gongfan Temple. The development and design of this product allows visitors to keep a souvenir of the scent and engage all of their five senses for a memorable experience (Figure 3, designed by Chang Tsen-Yao, Lin Hsuan-Chen, Liao En-Lin).



Figure 3. Sandalwood products.

\section{Magnifying Glass}

This product targets middle-aged and elderly worshippers. The development project involved products that are commonly used by middle-aged and elderly people in their daily activities. A magnifying glass was designed with wood carvings and sculptural elements of Gongfan Temple to enhance the usability and artistic quality of the product (Figure 4, designed by Chang Tsen-Yao, Yu Yun-Shih).

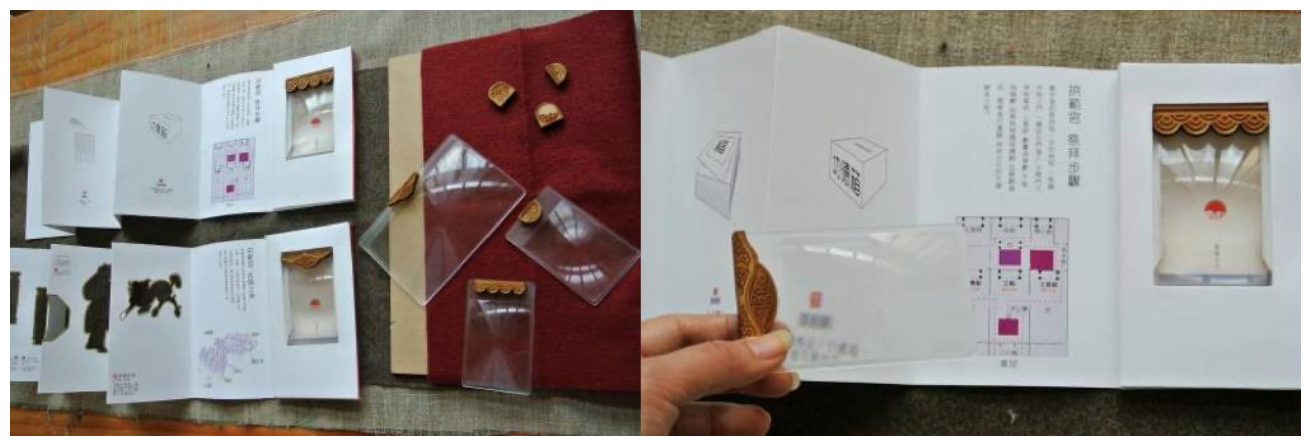

Figure 4. Magnifying glass.

The course, which covered Gongfan Temple, gave students the opportunity to engage in religious culture by conducting field observations, interviews, and investigation of local customs. According to their post-course opinions and feedback, the students were able to gain a deeper understanding of the Gongfan Temple culture and identity during their interactions with the locals:

"By chatting with them, we were able to let them comfortably discuss anything with us. Although we didn't necessarily get anything out of it, [the interaction] definitely allowed us to identify with the place and better understand its unique characteristics." (P2) 
"When [I was] at Gongfan Temple, there was a person who eagerly shared the temple's history and story, explaining the buildings and culture as well as the design of the building." (P6)

"My happiest moments during the process were the interviews and observations because I had the opportunity to engage with different people and hear their stories during our interactions." (P8)

After learning and absorbing all the information provided to them on various cultural history materials and local cultural characteristics, the students used service design tools to perform position analysis and subsequently produced concrete design products through design thinking and practices. The stages of the course design enabled students to transition from understanding to creation, inspiring them to explore culture in greater depth and making them realize the importance of local development and cultural sustainability.

"When planning products intended for seeking blessings, it is important to consider local environmental resources in order to facilitate development of the surrounding environment." (P5)

"[I] heard the stories behind each temple culture. Temples are the root of Taiwanese culture. Only by exhausting all efforts to preserve meaning can a culture be passed down through generations." (P7)

According to students' feedback, incorporating religious cultural issues into the learning process facilitates the sustainability of religious culture.

\subsection{Service Design Use: Transforming Problems to Design Performance}

With regard to course and implementation in Stages 2 and 3, field investigation and service design strategies were adopted to determine the existing problems in Gongfan Temple. Results showed that numerous conventions established through common practice were found at religious cultural sites such as Gongfan Temple. Since the majority of visitors were local residents and devotees, most of them did not need additional guides and information. Hence, Gongfan Temple did not provide any services and activities on-site.

However, changes in consumer experience and habits have shifted the attributes of tourism travel towards in-depth experience. As a national monument, Gongfan Temple is associated with years of history, buildings, and cultural assets, all of which are characteristics for developing the experience economy and religious cultural tourism that can boost local development as well as serve as a strategy for cultural preservation and promotion. The researchers of this study focused on the study location for the course design and project implementation. Through observations and a customer journey map, the stages that devotees experienced, along with the problems that they encountered throughout their visit, from arrival to departure, were examined.

According to observations, the tourists had no understanding of temple worship procedures; they either imitated or asked other people or discovered how to perform the act of worship themselves. The tourists generally did not stay in the temple after completing the worship process. As a national monument, Gongfan Temple houses six deities, whose history and stories are considered valuable, intangible cultural assets. If tourists are unable to understand the temple's historical background, as well as the underlying purpose of praying to these deities, the visitors' emotional attachment to the temple is weakened, hindering the effective communication of Gongfan Temple's rich cultural history.

After the problems were identified through service design, service design tools were used to strategically and systematically determine and uncover problems (deficiencies) that existed on-site. In field operations, the following experience aspects must be satisfied: before tourists' arrival, upon tourists' arrival at the temple, during tourists' temple journey, and after tourists' departure from the temple. The probability of problems occurring can be reduced and solutions can be proposed by introducing product design perspectives and strategies into the experience process. 
Hence, the solution proposed was a guidebook for Gongfan Temple (Figure 5, designed by Chang Tsen-Yao, Su Xiao-Wen), which was developed through design implementation. The Buddhist statue in the temple was redesigned to highlight its exterior characteristics, and simple color blocks were used to explain the meaning and background of each deity. In addition, the guidebook provides a map with a step-by-step process of worshipping a deity. With information visualization, the guidebook offers a solution to the lack of useful resources that tourists need when visiting the temple.

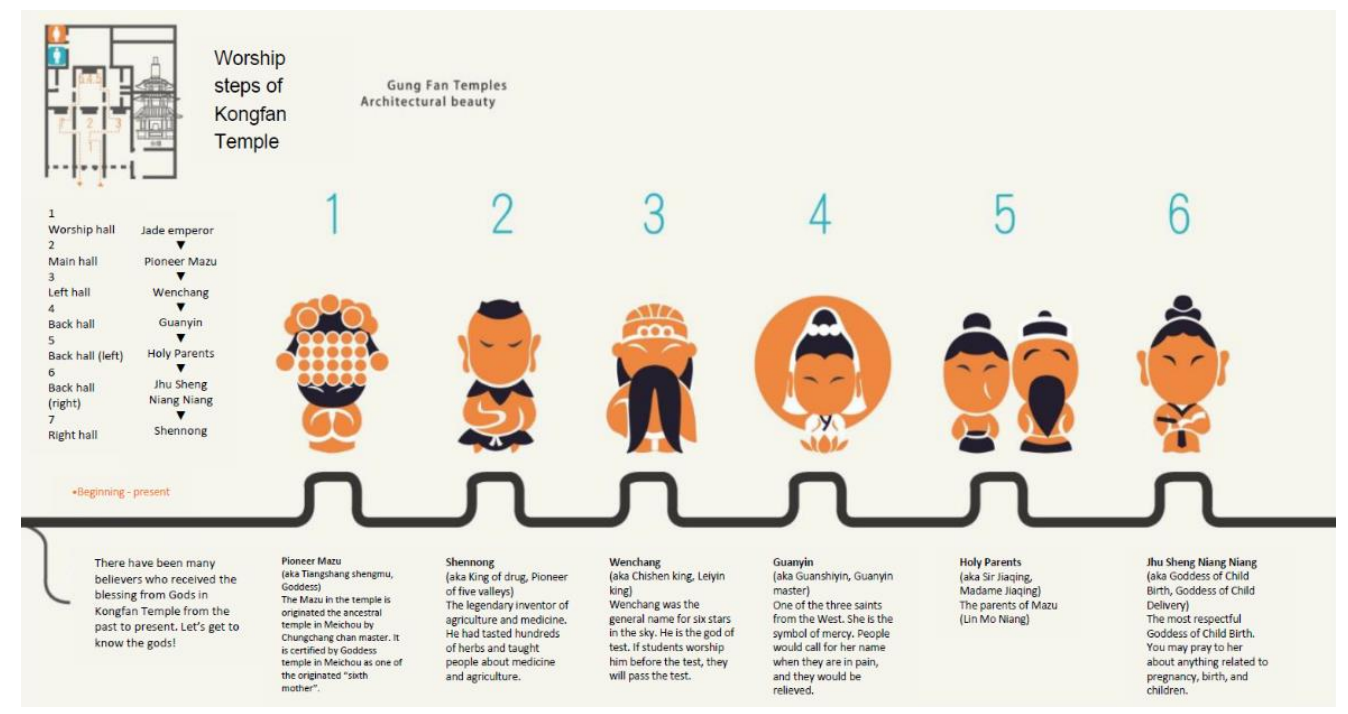

Figure 5. Inside pages of the Gongfan Temple guidebook.

Religious cultural sites are characterized by historical features that are filled with rich connotations of cultural, art, craftsmanship, and architectural values. These stories and knowledge must be effectively communicated to tourists to create affective memories and profound features of the site. Therefore, a brief profile of Gongfan Temple, including the history of the temple, the beauty of its architecture, and an itinerary for visitors, was developed using informative graphics and texts to strengthen the tourists' understanding of the temple and to cast light on the history, culture, and artistry of Gongfan Temple, serving as touchpoints for the preservation and communication of historical and cultural assets associated with Gongfan Temple.

In addition, information design and visual communication methods based on the customer journey map in service design were used to create an image of Gongfan Temple devotees who arrive and leave the temple as part of the worship procedures (as shown in Figure 6, designed by Chang Tsen-Yao, Su Xiao-Wen).

To complete a diagram of the worship process, on-site observations were required to identify the problems that visitors encounter during the worship process. Interviews with local residents and temple operators were also necessary to determine the order and procedure of worship. Subsequently, a drawing was completed through design interpretations. During this process, service design, information design, and layout design skills were integrated in order to complete the presentation. Finally, design strategies were used to propose solutions. 


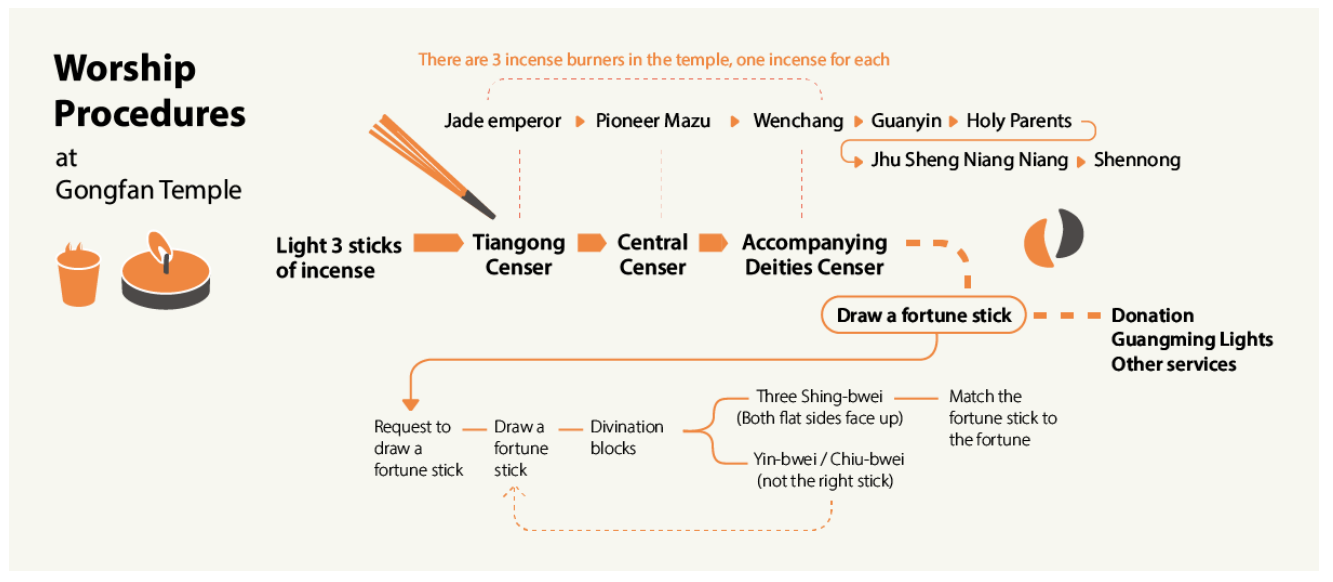

Figure 6. Worship procedures at Gongfan Temple.

\subsection{Discovering Design Elements: Interpreting and Recreating Traditional Codes}

In producing designs for Gongfan Temple, design items to be implemented must be confirmed and communicated with Gongfan Temple's operators. In this process, the operators proposed and described their requirements while the designers gave their opinions and views. In this stage, students gathered considerable elements and images from the religious cultural site through field observations and data collection, followed by summation and ideation. In the design process, the meaning of cultural elements must be understood and their applications must be analyzed for conversion into design ideas. Along with color schemes, styles, and code applications, a design application of religious cultural elements was completed (as shown in Figure 7).

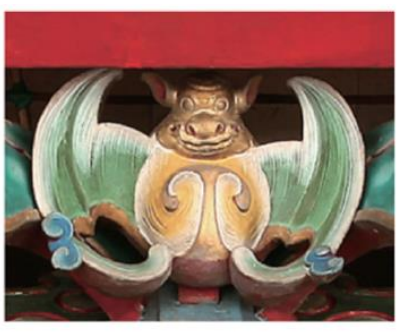

The original appearance of the architectural element of Gongfan Temple

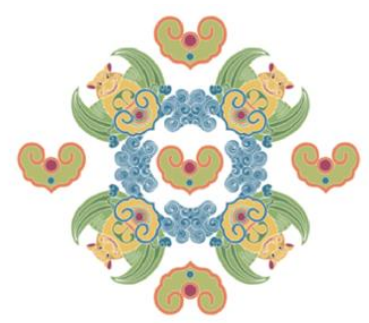

Design conversion and combination with other elements



Application of color schemes and combinations.

Figure 7. Design application and conversion of religious elements (compiled by this study).

In the third stage, the students presented design proposals and designed the finished products. A bag of rice distributed by the temple was selected for the design. Gongfan Temple is richly ornamented through creative and artistic craftsmanship. The carved beams and painted rafters on the pillars and stone walls convey a specific meaning, and these elements are also considered cultural assets of the temple. The patterns carved on the pillars and walls have their own symbolic meaning, from which five different connotations were extracted, and the images representing these meanings were used in the design. The five patterns represent blessings for pregnancy, long life, better fortune, safety, and education (as shown in Figure 8, designed by Chang Tsen-Yao, Liao Yi-Ting, Chou Shu-Lin, Tsai Ming-Yeh). 

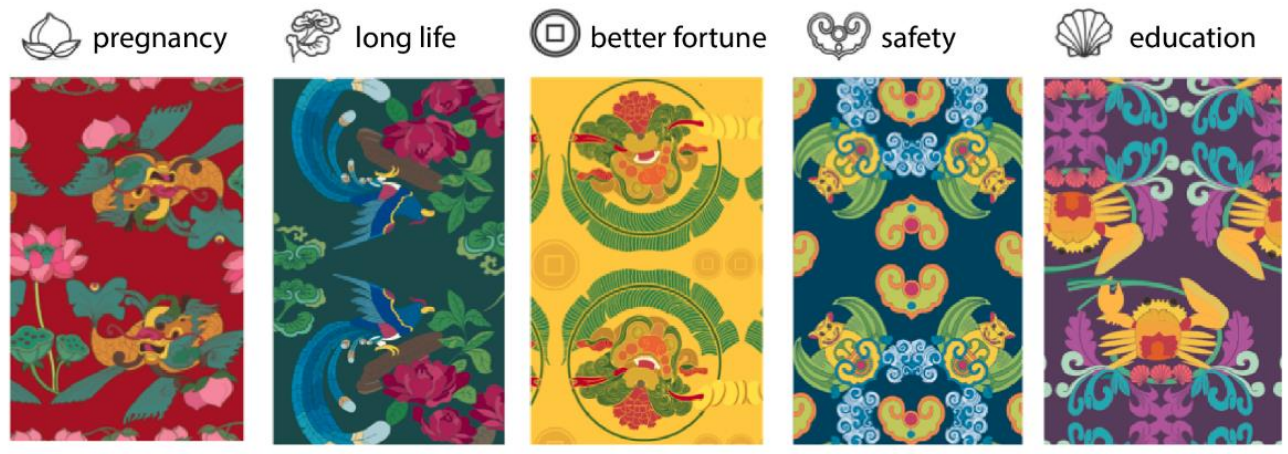

Figure 8. A totem designed with five meanings.

These five patterns were used and combined with culturally meaningful colors to create packaging with visually rich graphics and to strengthen the link between the product and religious cultural site. The resulting design was called Blessing of Matsu Temple (as shown in Figure 9, designed by Chang Tsen-Yao, Liao Yi-Ting, Chou Shu-Lin, Tsai MingYeh), which was a design competition entry that won the Red Dot Communication Design Award in 2016. The design was the project of Associate Professor Tseng-Yao Chang and her team of three third-year undergraduate students, who came up with the concept by first analyzing the totems and historical meanings of Gongfan Temple and created a new image design of the historical cultural artifact. In doing so, the artistic totems of Gongfan Temple were converted into patterns that have both function and preservation value. Colors were applied according to relevant cultural traditions to present the unique design and style of the ancient Gongfan Temple.

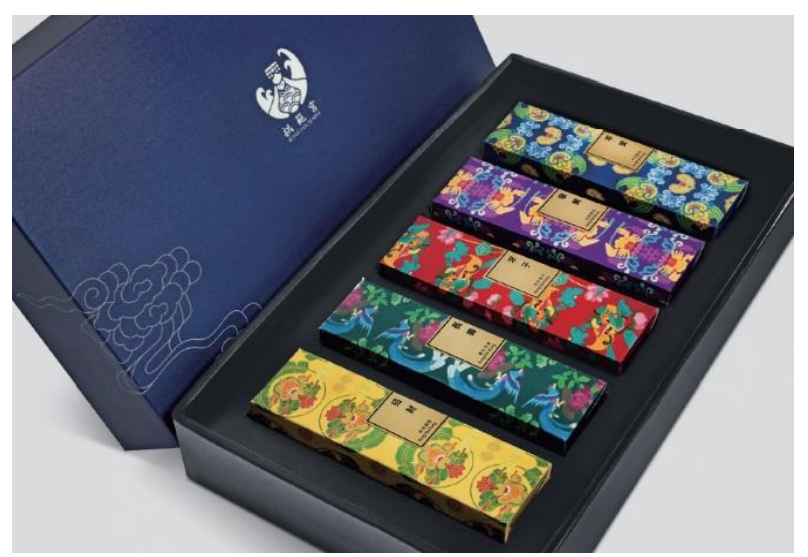

Figure 9. Using the Five Phases concept to design rice packaging.

\subsection{Introducing Culture into Courses: Towards Sustainability Branding}

This study incorporated teaching activities into religious culture, guiding students to observe local traditional practices, analyze meanings, and discover possible applications of cultural elements based on local cultural issues. Field observation enabled students to deeply grasp regional cultures, which is a crucial process for potential designers to cultivate their observation and communication skills. Figure 10 shows the strategy in which religious cultural designs are introduced in the course. This strategy also reflects Gongfan Temple's branding design, which entails addressing religious cultural issues and completing a step-by-step process involving reflection, revision, and supplementation, as well as a discussion with the client regarding brand positioning. 


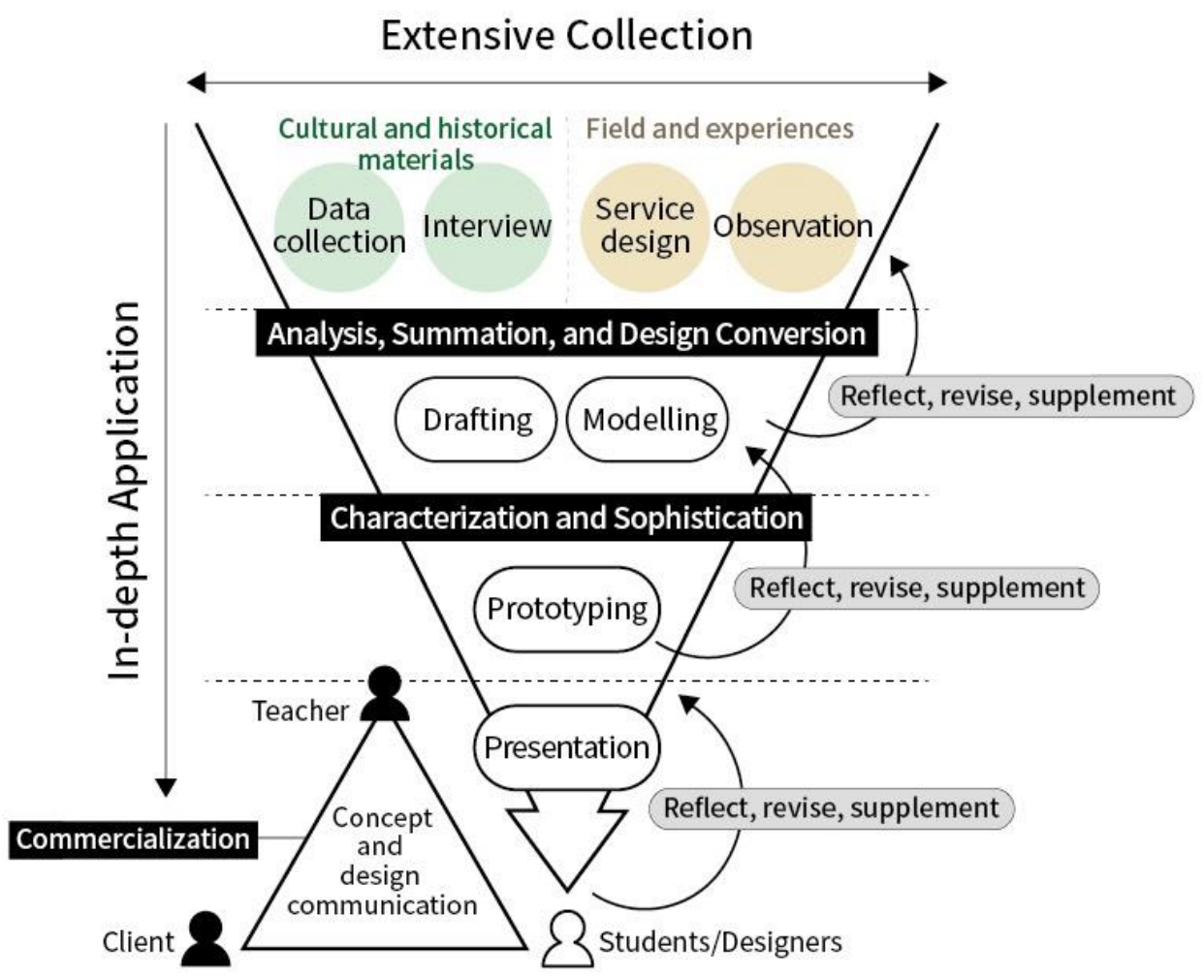

Figure 10. Strategy for incorporating religious cultural design in the course.

Traditionally, religious designs are largely derived from existing customs and styles, overlooking creativity, innovation, and unique cultural values. Through course integration, traditional religious cultural sites experience a breakthrough in terms of managerial thinking. Based on Gongfan Temple's past experience, the promotion of temple affairs relies on the collective discussion and coordination of committee members. However, not all committee members identify with the branding strategy discussed in committee meetings. When the students came up with design ideas using service design and brand strategies, a description of the design direction was also provided, helping internal members of Gongfan Temple to quickly reach a consensus and achieve goals relating to brand operation. When the course was integrated locally, design thinking strategies and methods were incorporated, and the students' creative design ideas were presented as physical design models that produced design value. The rich history, culture, and art of Gongfan Temple were concretely applied and extended outward. With Gongfan Temple as the center, which is connected to the development of the entire Mailiao Township and Yunlin County, the cultural preservation and operation of Gongfan Temple, as well as the design direction for establishing a coexisting and mutually supportive relationship with Mailiao Township, can be considered for model development to sustain and facilitate cultural preservation and regional management.

\section{Conclusions and Recommendations}

The development of Gongfan Temple as a brand has brought various design outcomes that demonstrated the breadth and depth of student learning and understanding of relevant design issues, as evidenced by the students' proposed solution (i.e., guidebook) and idea of integrating craftsmanship into product designs and applications. Several students presented human-centered product designs. They also collected considerable data based on field observations, interviews, and historical materials. They analyzed religious culture and local characteristics using divergent thinking, and they applied convergent thinking during ideation and discussion of designs. From conceptualization and drafting to simulation of commercial outcomes and presentation of finished products in relation to culture and 
locality, the students proposed product designs that possessed both cultural value and local characteristics (this process is shown in Figure 11).



Figure 11. The development and application of religious cultural design.

Since religious cultural sites are rich in culture, history, and art, they are closely linked to local religious life. This study recommends creating a brand in stages and making adjustments and changes after taking into account the reactions of local people. Future development can be considered based on the following: (1) rebranding temples using the culture and history of Gongfan Temple and creating a new image in line with contemporary lifestyles and local characteristics; (2) creating new images and meanings by improving the designs of Gongfan Temple's existing cultural products and packaging, and creating value for existing culture and traditional events/objects, which would in turn increase the value of local environment; and (3) creating sustainable tourism and cultural value through design planning, which would help to establish direction and value for the sustainable operation of local culture and tourism.

The research is conducted by the combination of the teaching design and practices projects to ensure that students have the opportunity to access the culture and legacy of local religion. Therefore, we can make sure that the related culture and cultural heritage are continuously considered, understood, and inherited. The researchers have been delving into the issue of cultural authenticity since $2012[51,52]$ and they forthwith recognized that designers have social responsibility when addressing the issue of "culture". Designers must discreetly examine whether designs are devoted to the cultural connotation of social demands or not and consider the value of social responsibility that designs should have. In this teaching process, students will be encouraged to show self-interpretation and conversion by the religious culture. To avoid applying and misunderstanding the culture, we provide historical notes and guidelines of architectural decoration as references. In addition, we invite the management committee of Gongfan Palace to participate in related discussion and semester-end performance. To summarize, we take this course as the opportunity to make a lasting impact and offer the chance to consider and interpret the 
implication of culture when students are facing different cultures. In addition, there are varieties of Taiwanese temples (which are dedicated to different deities), cultural history, and particular relics that are diversified; on the other hand, the religious culture of urban and rural development are quite dissimilar. This study takes a local temple, namely Gongfan Temple, as a single case for further research. The related methods of strategies will be applied in different religious fields to acquire different results that reflect the diversity of culture and the prospective forms of service design thinking to reflect this variability. It is suggested that subsequent research could examine different scales of religion, different religious cultures, or different lengths of time, and also consider the value of cultural sustainability in teaching processes.

Author Contributions: Conceptualization, T.-Y.C.; writing-original draft preparation, T.-Y.C. and Y.-J.C.; writing-review and editing, T.-Y.C.; visualization, revision, and supervision, T.-Y.C. All authors have read and agreed to the published version of the manuscript.

Funding: This research received no external funding.

Institutional Review Board Statement: Not applicable.

Informed Consent Statement: Not applicable.

Data Availability Statement: The data presented in this study are available on request from the corresponding author.

Conflicts of Interest: The authors declare no conflict of interest.

\section{References}

1. Ministry of Interior ROC. Nationwide Temple Statistics (Including Temples Owned by Foundations). Available online: https: / / religion.moi.gov.tw / ChartReport/Index?ci=1\&cid=2 (accessed on 10 March 2020).

2. Iliev, D. The evolution of religious tourism: Concept, segmentation and development of new identities. J. Hosp. Tour. Manag. 2020, 45, 131-140. [CrossRef]

3. Sung, T.T. Preface-the essence of service design and process tools. J. Des. 2014, 19, 1-8.

4. Løvlie, L.; Downs, C.; Reason, B. Bottom-line Experiences: Measuring the Value of Design in Service. Des. Manag. Rev. 2010, 19, 73-79. [CrossRef]

5. Ho, S.S.; Sung, T.T. The Development of Academic Research in Service Design: A Meta-Analysis. J. Des. 2014, 19, 45-66.

6. Sullivan, M.; Keesing, R.M. Cultural Anthropology: A Contemporary Perspective; Wadsworth Publishing: Belmont, CA, USA, 1989; Volume 54, p. 231.

7. Warnier, J.P. La Mondialisation de la Culture; La Découverte: Paris, France, 2003.

8. Chu-Shore, J. Homogenization and Specialization Effects of International Trade: Are Cultural Goods Exceptional? World Dev. 2010, 38, 37-47. [CrossRef]

9. Yen, S. The Future I have Seen; Common Wealth Magazine: Boston, MA, USA, 2008.

10. Ministry of Culture ROC. 2016 Summary Report of Cultural Tourism Output Estimates. Available online: https://stat.moc.gov. tw / Research_Download.aspx?idno=1112 (accessed on 10 March 2020).

11. Goeldner, C.R.; Ritchie, J.R. Tourism: Principle Practice, Philosophies, 11th ed.; John Wiley \& Sons: Hoboken, NJ, USA, 2006.

12. Rinschede, G. Forms of religious tourism. Ann. Tour. Res. 1992, 19, 51-67. [CrossRef]

13. Vukonić, B. Medjugorje's religious and tourism connection. Ann. Tour. Res. 1992, 19, 79-91. [CrossRef]

14. Organization for Economic Cooperation and Development. The Impact of Culture on Tourism; OECD: Paris, France, 2009.

15. Lin, H.-H.; Ling, Y.; Lin, J.-C.; Liang, Z.-F. Research on the Development of Religious Tourism and the Sustainable Development of Rural Environment and Health. Int. J. Environ. Res. Public Health 2021, 18, 2731. [CrossRef]

16. Chen, H.; Rahman, I. Cultural tourism: An analysis of engagement, cultural contact, memorable tourism experience and des-tination loyalty. Tour. Manag. Perspect 2018, 26, 153-163. [CrossRef]

17. Otto, J.E.; Ritchie, J.R.B. The Service Experience in Tourism. In Tourism Management: Towards the New Millennium; Ryan, C., Page, S., Eds.; Elsevier Science Ltd.: Oxford, UK, 2000.

18. Yan, N.; Halpenny, E. The role of cultural difference and travel motivation in event participation: A cross-cultural perspective. Int. J. Event Festiv. Manag. 2019, 10, 155-173. [CrossRef]

19. Liat, C.B.; Nikhashemi, S.; Dent, M.M. The chain effects of service innovation components on the building blocks of tourism destination loyalty: The moderating role of religiosity. J. Islam. Mark. 2020. ahead of print. [CrossRef]

20. Cugini, A. Religious tourism and Sustainability: From Devotion to Spiritual Experience. In Tourism in the Mediterranean Sea; Grasso, F., Sergi, B.S., Eds.; Emerald Publishing Limited: Bingley, UK, 2021; pp. 55-73.

21. Hong, S.H.; Hsieh, D.W. Discussion on the Cultural and Tourism Value of Religions. Buddhism Sci. 2010, 11, 11-20.

22. Lash, S.; Urry, J. Economies of Signs and Space; Sage Publications: Newbury Park, CA, USA, 2002. 
23. Rifkin, J. The Age of Access: The New Culture of Hyper Capitalism-Where All of Life is a Paid-For Experience. Radic. Teach. 2002, 63, 36-39.

24. Saco, R.M.; Goncalves, A.P. Service Design: An Appraisal. Des. Manag. Rev. 2010, 19, 10-19. [CrossRef]

25. Wei, W.L.; Lu, M.T. Influence of Product Form Attributes on Visual Complexity and Consumer Preferences. J. Des. 2019, 24, 49-69.

26. Jensen, R. The Dream Society: The Coming Shift from Information to Imagination; McGraw-Hill: London, UK, 1999.

27. Verganti, R. Design-Driven Innovation-Changing the Rules of Competition by Radically Innovating What Things Mean; Harvard Business Press: Boston, MA, USA, 2009.

28. Delaney, M.; McFarland, J.; Yoon, G.H.; Hardy, T. Global Localization, Innovation—Global Design and Cultural Identity, Summer, 46-49; 2002. Available online: https://www.idsa.org/sites/default/files/xiglafiles/summer02_samsung.pdf (accessed on 9 May 2020).

29. Moalosi, R.; Popovic, V.; Hickling-Hudson, A. Product analysis based on Botswana's postcolonial socio-cultural perspective. Int. J. Des. 2007, 1, 35-43.

30. Brown, T. Change by Design: How Design Thinking Transforms Organizations and Inspires Innovation; Harper Business: New York, NY, USA, 2009.

31. Keller, K.L. Conceptualizing, measuring, and managing customer-based brand equity. J. Mark. 1993, 57, 1-22. [CrossRef]

32. Aaker, D.A. Building Strong Brands; The Free Press: New York, NY, USA, 1996.

33. Hankinson, P. Brand orientation in the charity sector: A framework for discussion and research. Int. J. Nonprofit Volunt. Sect. Mark. 2001, 6, 231-242. [CrossRef]

34. Huang, S.M. Exploring a Missing Link for the Brand Image Effect on Brand Loyalty: The Mediated Path of the CAC Extending Model. J. Manag. 2017, 34, 1-29.

35. Keller, K.L. Strategic Brand Management: Building, Measuring, and Managing Brand Equity; Prentice-Hall: Upper Saddle River, NJ, USA, 1998

36. Kim, H.-K.; Lee, T.J. Brand Equity of a Tourist Destination. Sustain. J. Rec. 2018, 10, 431. [CrossRef]

37. Daldanise, G. From Place-Branding to Community-Branding: A Collaborative Decision-Making Process for Cultural Heritage Enhancement. Sustain. J. Rec. 2020, 12, 10399. [CrossRef]

38. Notarstefano, G.; Gristina, S. Eco-Sustainable Routes and Religious Tourism: An Opportunity for Local Development. The Case Study of Sicilian Routes. In Tourism in the Mediterranean Sea; Grasso, F., Sergi, B.S., Eds.; Emerald Publishing Limited: Bingley, UK, 2021; pp. 217-239.

39. Sangiorgi, D. Transformative services and transformation design. Int. J. Des. 2011, 5, 29-40.

40. Moritz, S. Service Design: Practical Access to an Evolving Field. Unpublished. Master's Thesis, Köln International School of Design, Cologne, Germany, 2005. Available online: https:/ / uploads.strikinglycdn.com/files /280585/5847bd6a-e928-4f0f-b677 -ed7df26fa1df/Practical\%20Access\%20to\%20Service\%20Design.pdf (accessed on 10 January 2020).

41. Yang, C.F.; Sung, T.J. Service design for social innovation through participatory action research. Int. J. Des. 2016, 10, 21-36.

42. Yin, P.N. Historic Cities, Representation of Architecture and Cultural Tourism: A Case Study on Tang Paradise in Xian City, China. J. Des. 2011, 16, 23-43.

43. Clatworthy, S. Service innovation through touch-points: Development of an innovation toolkit for the first stages of new service development. Int. J. Des. 2011, 5, 15-28.

44. Chang, Y.C. Religious Tourism and Research in Taiwan: An Approach of Essentialism and Methodology. Yu Da Acad. J. 2011, 27, 65-84.

45. Hollins, G.; Hollins, B. Total Design: Managing the Design Process in the Service Sector; Pitman Publishing: London, UK, 1991.

46. Kelley, T.; Littman, J. The Ten Faces of Innovation: IDEO's Strategies for Beating the Devil's Advocate E Driving Creativity Throughout your Organization; Currency/Doubleday: New York, NY, USA, 2005.

47. Huang, C.-E.; Liu, C.-H. The creative experience and its impact on brand image and travel benefits: The moderating role of culture learning. Tour. Manag. Perspect. 2018, 28, 144-155. [CrossRef]

48. Pine, B.J.; Gilmore, J.H. Welcome to the experience economy. Harv. Bus. Rev. 1998, 76, 97-105. [PubMed]

49. Janonis, V.; Virvilaitè, R. Brand image formation. Eng. Econ. 2007, 2, 78-90.

50. Design Council. The Design Process: What is the Framework for Innovation? Design Council's Evolved Double Diamond. Available online: https://www.designcouncil.org.uk/news-opinion/design-process-what-double-diamond (accessed on 18 March 2020).

51. Chang, T.Y.; Wen, C.T. Cultural Authenticity in Culture-Driven Products: The Communication of Cultural Messages. In Pioneering Minds Worldwide: On the Entrepreneurial Principles of the Cultural and Creative Industries; Hagoort, G., Thomassen., A., Kooyman, R., Eds.; Eburon Academic Publishers: Utrecht, The Netherlands, 2012; pp. 146-151.

52. Chang, T.Y.; Wen, C.T. Discover the Root: Construction of Authenticity in Culture-Driven Products. Appl. Mech. Mater. 2013, 311, 354-359. [CrossRef] 